\title{
O livro didático de língua portuguesa no Brasil
}

\section{The didatic book about the portuguese in the Brazil}

\author{
Ivete Aparecida da Silva Ota*
}

\begin{abstract}
RESUMO
Este trabalho tem como objetivo refletir a respeito do livro didático no Brasil, de forma generalizada, e, mais especificamente, sobre o livro didático de Língua Portuguesa, e está dividido em dois momentos. O primeiro discute a construção sócio-hitórica do Livro Didático: como este objeto foi se caracterizando ao longo do tempo, ganhando espaço e se constituindo num discurso de autoridade através das relações de poder por ele instituídas na sala de aula. Discute ainda as estratégias de marketing que o fazem objeto de consumo. O segundo momento se volta, de forma mais específica, para o Livro Didático de Língua Portuguesa e as concepções metodológicas (e interesses mercadológicos): a concepção de leitura e o trato com o texto, sob a influência de diferentes teorias. Nesta parte, o estudo centra foco na proposta de abordagem de diferentes gêneros textuais. Para esta análise, o estudo contou com o referencial teórico da Semiótica Discursiva e apontou, como resultado das investigações, a grande lacuna que ainda existe com relação à abordagem de textos de diferentes gêneros no que diz respeito aos mecanismos de construção de sentido.

Palavras-chave: livro didático de língua portuguesa; gêneros textuais; mecanismos de construção de sentido.
\end{abstract}

* Mestre em Educação pela Universidade Federal do Espírito Santo (2004), doutoranda em Linguística pela Universidade Federal de Alagoas. Professora titular da Faculdade de Formação de Professores de Petrolina e Professora titular do Instituto Federal do Sertão Pernambucano Petrolina-PE. 


\begin{abstract}
This work has as its objective to reflect on the didactic book in Brazil, in a generalized way, but specifically about the portuguese language which is divided into two sections. The first sections talks about the social history of the didactic book: the objective was being built through time, gaining space and constituting itself in authoritarian speeches through power relations being instituted in the classroom. Discusses the strategies of marketing which makes it an object of consumption. The second section is based on, specifically, the didactic book of portuguese language and its methodology conceptions (and interest in marketing): the concept on how the text and reading are treated under the influence of different theories. This section of the study is focused on the proposal of how the different kinds of texts will be broached. To get to these analyses, the study counted on the theoretical reference of the Discursive Semiotics and it pointed out that, as a result of the investigations, the big gap which still exists is talking about how the different kinds of texts are broached, telling us the direction of its construction mechanisms.

Keywords: didactic book of portuguese; kinds of text; constructions mechanism of direction.
\end{abstract}

\title{
Introdução
}

Devido à importância que o livro didático adquire no cotidiano escolar brasileiro, este artigo tem como objetivo trazer algumas reflexões a respeito da inserção e do papel desse material na sala de aula, bem como a maneira como o Livro didático de Língua Portuguesa trabalha o texto, especialmente os que se constituem a partir da mobilização das linguagens verbal e visual, já que grande parte dos textos que circulam socialmente é construída a partir da articulação de diferentes linguagens. Obviamente, não se pretende aqui esgotar ou fechar o assunto, mas pontuar algumas questões que possibilitem um olhar crítico para este objeto. As reflexões aqui colocadas integram a dissertação de Mestrado intitulada Textos verbais/visuais no livro didático de língua portuguesa: uma análise dos mecanismos de construção de sentido e da leitura proposta.

No Brasil, o termo livro didático, que depois se tornaria tão comum e tão familiar ao ambiente escolar, segundo Baldissera aparece pela primeira vez no Decreto-Lei no. 1006, de 30 de dezembro de 1938, Artigo 2., Parágrafo $1^{\circ}$. 
Compêndios são livros que exponham total ou parcialmente a matéria das disciplinas constantes dos programas escolares. Parágrafo $2^{\circ} .:$ livros de leitura de classe são livros usados para a leitura dos alunos em aula; tais livros também são chamados de livro de texto, livro texto, compêndio escolar, livro de classe, manual, livro didático (BALSISSERA, apud PINTO, 2001, p. 22).

Assim instituído oficialmente, esse recurso didático foi adquirindo feições peculiares ao longo do tempo na medida que ia atendendo a públicos, interesses, ideologias e contextos históricos diferentes.

Mas, é com o advento da expansão da educação no Brasil que o Livro Didático (de agora em diante LD) passa a assumir um papel preponderante na sala de aula em virtude das significativas transformações por que passa o sistema educacional, em função da nova clientela que adentra a escola.

Com a grande demanda das classes populares pela educação, o que se viu foi a escassez de professores que os cursos rápidos de formação tentaram suprir, provocando uma formação profissional deficiente, resultado da falta de embasamento teórico, o que foi ocasionando a desvalorização do/a profissional da educação.

Em virtude disso, professores e professoras, assim como o corpo discente, antes advindo da elite e por isso com acesso à leitura e aos bens culturais, agora são oriundos das camadas populares, expropriadas dessas possibilidades. É um novo contingente de corpo docente e discente a adentrar o espaço da escola e constituir uma outra realidade escolar que o sistema de ensino não está preparado para administrar.

Em consequência desses aspectos - professores e professoras desprovidos do acesso a bens culturais e mal formados - veio a desvalorização gradativa do trabalho docente, trazendo consigo os baixos salários e o acúmulo de aulas, o que acaba intensificando ainda mais esse processo de desvalorização.

É nesse contexto que o LD se insere de forma decisiva, vindo suprir as deficiências da formação ao trazerem roteiros preestabelecidos, conteúdos já selecionados e mesmo respostas prontas, automatizando,

a um tempo o mestre e o aluno, reduzidos a máquinas de repetição material. [...] Assim, a solução para o despreparo do professor em dado momento parece simples: bastaria oferecer-lhe um livro que sozinho ensinasse aos alunos tudo que fosse preciso (GERALDI, 1997, p. 117). 
A presença do livro didático vai se firmando massivamente na sala de aula, constituindo-se em muitos casos, segundo Coracini (1999, p. 17), a única fonte frequente de leitura de professores e professoras, uma vez que, segundo sua pesquisa, os professores de ensino médio com os quais trabalhou não costumavam ler textos que contivessem mais de uma página, exceto romances ou textos sobre o ensino.

Esse discurso é reiterado pela Secretaria de Educação Fundamental (SEF), pertencente ao MEC (Ministério da Educação), ao constatar que esta se constitui fonte quase que exclusiva de transmissão de conhecimentos no ambiente escolar, devido à falta de acesso a outros materiais de estudo e de pesquisa para alunos e alunas e, muitas vezes, para os professores e professoras, bem como única fonte de referência do trabalho em sala de aula, ou por falta de acesso ou porque os roteiros preestabelecidos e com respostas prontas representam economia de tempo e de reflexão na preparação das aulas, fazendo desses livros verdadeiros manuais a serem seguidos.

E, como há uma deficiência muito grande nas políticas de formação continuada, o LD acaba funcionando, muitas vezes, como mecanismo de atualização profissional ainda que não seja essa sua função. Assim, um instrumento que deveria ser visto de forma crítica acaba por orientar o trabalho docente. Tudo isso vem refletir o descaso a que tem sido submetida a educação brasileira e a profissionalização do professor.

Diante do inegável espaço que o LD, bem ou mal, reconhecidamente ocupa, o MEC institucionaliza um conjunto de políticas de avaliação, aquisição e distribuição de livros didáticos para a Escola Pública de nível fundamental, através do PNLD (Programa Nacional do Livro Didático), embora nem sempre os critérios de escolha da escola sejam os mesmos propostos pelo Programa, dada a influência de um poderoso jogo de marketing por parte das editoras.

Mesmo sendo alvo de muitas críticas nos últimos anos, não é possível simplesmente descartá-lo, em virtude da herança cultural e mesmo do seu papel junto a muitos docentes que veem nele a muleta que sustenta seu fazer pedagógico, acompanhando-o - fiéis seguidores - do princípio ao fim e, ao contrário do que se diz, reiterando Geraldi (1997), não é o professor que adota o LD; mas, o professor é adotado pelo LD, devido a uma série de fatores, tais como: as facilidades que o LD proporciona, a escassez de materiais didáticos, falta de uma política de formação adequada. 


\section{O livro didático e o discurso de autoridade}

A presença massiva do LD na escola vem revelá-lo detentor de um discurso de autoridade por duas razões: primeira, em virtude de ser, muitas vezes, o único recurso didático e de informação na escola, acaba adquirindo estabilização e legitimidade ao definir abordagens, propor e sistematizar conteúdos, mesmo que essa seleção de conteúdos esteja atrelada às instâncias superiores de educação.

Enfim, com relativa liberdade, o LD define, segundo Coracini (1999, p. 12), o quê e como ensinar/aprender, o que acaba engessando o fazer pedagógico uma vez que, ainda segundo a autora, a estrutura e procedimentos, mesmo quando o LD não é utilizado, acaba se refletindo no material produzido pelo professor, testemunhando internalização de formas consagradas pelo LD, nacional e internacional.

A segunda razão deve-se à aura de veracidade em torno da escrita e especialmente do LD, que faz com que este se constitua como a fonte de saber pronto e acabado, autorizando o professor, implicitamente, a adotá-lo de forma sistemática e exigir do aluno a assimilação e, em alguns casos, respostas idênticas ao que está posto no manual do professor.

No caso do livro de Língua Portuguesa, "a interpretação já está pronta, esperando para ser dita - ou escrita. As atividades do LD não dão margem a deslizes, a outras leituras, a posicionamentos ou a questionamentos. $\mathrm{O}$ texto tem uma estrutura e um sentido; a tarefa do aluno é captá-los" (GRIGOLETTO, 1999 , p. 70) e transferi-los para as respostas dadas aos exercícios; respostas que muitas vezes são induzidas e direcionadas pelas perguntas e encontram-se explícitas nos textos, cabendo ao aluno apenas localizar. Essa postura deixa à mostra a concepção de educação aí investida: uma educação baseada na reprodução de conhecimentos.

O LD, nas condições acima, acaba sendo a instância máxima de saber e de um saber que parece cristalizado, pronto e acabado. E, sendo o detentor desse saber, é o responsável por sua transmissão de forma mais "digerível” e atraente, mesmo dos conteúdos mais complexos, o que acaba, às vezes, por gerar uma abordagem superficial e descontextualizada. 


\section{Livro didático: um bem consumível}

O LD ocupa um espaço reconhecidamente considerável, seja sendo utilizado diretamente pelo aluno ou como material de consulta pelo professor que, mesmo adotando determinado livro didático, comumente, recorre a outros para esclarecer dúvidas e colher sugestões. Isso explica o grande interesse por parte de pesquisadores em torno do assunto.

Esse material é sedutor por possuir a característica, por um lado, de propiciar praticidade ao trabalho pedagógico, embora, às vezes, seja uma praticidade acrítica, alienante e, por outro lado, de ser agradável e atrativo aos olhos de quem lê, uma vez que há uma preocupação crescente com o aspecto visual através de projetos gráficos cada vez mais atraentes.

Devido ao espaço que lhe é destinado na escola, principalmente depois do PNLD, que ao lado da implementação de políticas de avaliação, passou a distribuir sistematicamente nas escolas públicas de Ensino Fundamental, o LD é hoje a grande vedete do mercado editorial brasileiro, responsável pela grossa fatia de $60 \%$ das vendas de livros no Brasil, segundo Marques Neto (2003). Desse percentual de vendas, o MEC é responsável pela compra de 50\%, segundo a Assessoria de Comunicação desse órgão, sendo que a intenção é ampliar esses números. Isso explica a preocupação constante das editoras em oferecer um produto, comercialmente, cada vez mais interessante, mais competitivo, capaz de se manter no mercado. O livro que fará mais sucesso será aquele que conseguir vender por mais tempo.

O adjetivo "didático" faz do livro um objeto peculiar, imprimindo-lhe um caráter comercial, mercadológico, que faz dele um bem consumível, um produto descartável que, para fomentar o mercado, precisa fazer constantes revisões das edições, tornando desatualizadas as publicações anteriores. E, assim perecíveis, carecem de atualização constante para atender às regras do mercado capitalista, representando lucro. Outros livros são mais duradouros, como é o caso das enciclopédias, romances, dicionários e os livros teóricos nas respectivas áreas. O caráter "didático" o torna perecível e descartável, produto de consumo, bem como um material que tem que se adequar, pelo menos teoricamente, às faixas etárias e ao nível de desenvolvimento intelectual do aluno.

Nem sempre ser o livro mais vendido significa ser o melhor do ponto de vista didático; mas, pode ser o resultado de estratégias de marketing bem montadas para a manutenção do monopólio de algumas poucas editoras, visando interferir no processo de aquisição junto às escolas: fornecimento de livros e de brindes aos professores, coordenadores e diretores, folhetos e catálogos de 
propaganda, cursos de divulgação das obras, presença dos representantes nas escolas para convencer o corpo docente na escolha dos livros, além de um material visualmente cada mais atrativo e de encartes que facilitam o trabalho do professor e da professora, tais como respostas às questões propostas, planos de ensino e sugestão de avaliação.

Além das estratégias de divulgação desse material, a batalha pelo mercado arma-se de mecanismos de apresentação como recursos visuais coloridos, cheios de imagens e com projetos gráficos arrojados, buscando chamar a atenção de alunos e alunas, de professores e de professoras, na tentativa de atrair-lhes o olhar e angariar-lhes o interesse. Construída para produzir encantamento, sedução e prazer sensorial, essa relação do objeto-livro com o leitor, ao longo de um período que dura normalmente um ano letivo, tem como objetivo envolver e fazer-se aceito, predispondo esse leitor a uma relação pacífica. E, obviamente, fazer vender. A primeira reação, em geral, diante de um livro novo é sempre de passar a vista em busca do que de mais chamativo o livro possa apresentar: as cores, as imagens, os títulos.

Diante do papel do livro didático, quer como manual, quer como produto de consumo, é necessário o olhar crítico do professor, da professora para não ser massificado por interesses alheios à educação de qualidade. A vivência tem mostrado que os cursos de formação de professores não contemplam a análise do material didático e que a formação acadêmica, ao longo desses cursos, não possibilita uma reflexão/conscientização da relação teoria/prática que fundamente o profissional para uma análise crítica do material didático que lhe é oferecido.

\section{O livro didático de língua portuguesa}

Nesse contexto, insere-se o livro didático de língua portuguesa que, seja para atender a objetivos pedagógicos ou para torná-lo um produto vendável, vai buscando, pelo menos aparentemente, simular um discurso de adequação às mudanças de concepção pelas quais passa o ensino de língua, para continuar garantindo seu espaço na sala de aula.

Segundo Bezerra (2001) o LD de Língua Portuguesa, nos moldes em que se apresenta hoje - com textos, vocabulário, interpretação, gramática, redação e ilustração - surgiu no fim dos anos 60, consolidando-se na década de 70 . Segundo a autora, nos anos 60, a concepção de texto subjacente limitava-se ao texto literário, por visar à expressão do belo, cabendo aos estudantes imitar, na escrita, os modelos consagrados. 
Nos anos 70, por influência da Linguística Estrutural e da Teoria da Comunicação, a concepção de texto no LD começa a se ampliar, com a inserção, ao lado do texto literário, de textos jornalísticos e de histórias em quadrinho. Havia então uma ênfase excessiva nos elementos da comunicação (emissor, receptor, mensagem, código, canal e referente), que predominou até metade dos anos 80 , quando começa a concorrer com uma concepção de texto de caráter pragmática, que leva em conta critérios de coerência, coesão, situacionalidade, informatividade, aceitabilidade, etc.

Em decorrência dessa compreensão, fruto dos estudos de Bakhtin, compreendeu-se compreendeu-se que os textos orais e escritos que se produzem, e através dos quais há interação social, organizam - se em torno de características mais ou menos estáveis, que configuram os gêneros textuais, devendo, portanto, as atividades relativas ao ensino/aprendizagem de textos se orientarem a partir dessa concepção.

A partir dos estudos sociolinguísticos, o eixo do ensino-aprendizagem de língua portuguesa passa a ser o texto em sua função social, a partir das características próprias de cada gênero, articulado a interesses e necessidades de uma dada sociedade. Em função disso, o livro didático de língua portuguesa passa a centrar aí o seu foco, pelo menos teoricamente.

A pesquisa realizada sobre textos verbais/visuais no Livro Didático de Língua Portuguesa aponta que nos LDs a preocupação em mostrar uma grande quantidade de gêneros textuais torna-se mais uma necessidade de atender a um modismo que propriamente trabalhar a textualidade, o que acaba por fragilizar a abordagem limitando-a à estrutura, ao assunto e, à linguagem de cada gênero. Não há uma preocupação com a construção da textualidade, com a construção do sentido, com os mecanismos de dizer. Assim, à semelhança do que ocorria outrora, a preocupação em identificar os elementos da comunicação cede lugar à preocupação em identificar a estrutura do texto.

Obviamente, não se pretende aqui questionar a validade de se trabalhar a língua a partir dos gêneros, mas a forma de abordagem do texto. A grande preocupação parece ser mostrar-se atualizado, conectado com as novas concepções ao apresentar uma gama muito grande de gêneros textuais, sem aprofundar as discussões com relação aos modos de significação de cada texto. É a quantidade se impondo sobre a qualidade.

Em detrimento disso, por um lado, as perguntas sobre o texto se situam num nível de compreensão literal, prendendo-se apenas a aspectos superficiais, geralmente, na sequência em que aparecem no texto, valorizando quase sempre a apreensão de fatos e/ou ideias e a estruturação. Além disso, as respostas que o LD espera dos alunos geralmente já estão direcionadas nas perguntas, o aluno só terá que identificá-las, poupando-lhe do confronto com o texto e de uma 
investigação mais aprofundada.

Por outro lado, embora os livros apareçam recheados de imagens, essas imagens funcionam apenas como recurso para chamar a atenção. A discussão sobre gêneros textuais traz consigo duas outras discussões: a) o que é texto? b) Os textos, nos seus diferentes gêneros e intencionalidades, constituem-se apenas da linguagem verbal?

Se por texto entende-se um objeto sócio-historicamente produzido, dotado de significação e intencionalidade, envolvendo sujeitos que têm algo a dizer para alguém e nesse dizer estabelece interlocução, então por texto compreende-se o objeto que engendra mecanismos próprios de dizer, é dotado de especificidade e perpassa valores e ideologias da sociedade na qual se inserem, conforme aponta Barros, 1988:

Por texto entende-se: a) a organização e estruturação que engendra um "todo de sentido", objeto de significação; b) objeto de comunicação entre dois sujeitos, culturalmente construído numa sociedade de classes e determinados por formações ideológicas (BARROS, 1988, p. 130).

A sociedade contemporânea impõe através de diferentes mídias, cada vez com mais frequência e de forma mais elaborada, a presença da imagem sozinha ou associada à linguagem verbal para dizer, persuadir, emocionar, envolver, explicitar, ocultar, etc. Nessa perspectiva, e a partir do que se compreende como texto, a imagem, sozinha ou articulada à linguagem verbal, é um texto. E o que se detectou na pesquisa anteriormente citada é que embora a presença da imagem seja intensa no LD, funciona quase sempre como forma de chamar a atenção, distrair o olhar ou como pretexto. Ou seja, o texto visual/ imagético não é tratado como texto, dotado de mecanismos próprios de dizer e que se deve ser entendido como tal.

\section{Considerações finais}

Faz-se necessário pontuar que o LD enquanto objeto sócio-historicamente construído encontra-se situado em momento e em contexto determinados. No Brasil, o processo de leitura enquanto ato de reflexão foi por um longo período cerceado pela ditadura militar, que reestruturou ou até mesmo eliminou do 
currículo escolar disciplinas que pressupunham a leitura crítica.

No bojo desses acontecimentos, o resgate do papel da leitura na escola, seja em Língua Portuguesa ou em outras disciplinas, é um grande desafio para a escola. E o LD precisa estar comprometido a enfrentar. É necessário ampliar a concepção de texto veiculada que, embora traga para sala de aula a imagem ou o texto verbal/imagético, faz para atender a uma proposta de trabalho que está na moda: a partir dos gêneros textuais, mas, os diferentes gêneros são constituídos por diferentes linguagens. Mesmo o texto verbal é tratado de forma muito superficial, encarado apenas a partir de aspectos formais.

Assim como o texto verbal, o texto visual/imagético se constitui de mecanismos próprios de dizer, entre eles, a escolha de cores, a distribuição gráfica, a seleção de imagens, a escolha das formas, o tamanho e tipo de letras que para além da linguagem verbal, tornam-se recursos visuais.

Ao se propor a trabalhar diferentes gêneros textuais e considerando que os gêneros não se compõem somente da linguagem verbal, esses aspectos inerentes à linguagem imagética/visual não podem ser desconsiderados.

Assim, o que se percebe é que enquanto alguns setores da sociedade exploram todo o poder de significação da imagem, sozinha ou em textos sincréticos, o LD ainda não se deu conta da sua importância enquanto texto, já que o objetivo central do ensino de língua deve estar voltado para o texto, e não oferece um aparato teórico-metodológico para leitura de imagens, o que se constitui em grande lacuna, principalmente quando se propõe a trabalhar os diferentes gêneros textuais: esses gêneros não compostos simplesmente pela linguagem verbal. Ainda é importante ressaltar que mesmo no trato com o verbal, aspectos importantes da construção do sentido são não discutidos, como por exemplo, a escolha lexical, seleção dos tempos e modos verbais, extensão dos parágrafos, polifonia, discurso direto e indireto, entre outros.

Esse fato revela um dado preocupante que encontra eco nas discussões mobilizadas pela comunidade escolar e pela sociedade em torno da qualidade do ensino: a deficiência na leitura e na escrita do aluno. O LD, por ser um recurso que, como se viu, desfruta de um espaço privilegiado na escola, chegando mesmo, em alguns casos, a ser o único material de leitura de professores e alunos, precisa se voltar, em nome da qualidade do ensino, de forma mais aprofundada para a leitura dos diferentes gêneros textuais, de fato.

Como se pode observar, a hierarquização da escrita pelo LD mutila tanto a significação como a maneira própria de cada texto significar por não compreender esses elementos num processo de sincretismo, em que as linguagens se unem na construção de um sentido. 


\section{REFERÊNCIAS}

BARROS, D. L. P. de. Teoria semiótica do texto. São Paulo: Ática, 1990. . Teoria do discurso: fundamentos semióticos. São Paulo: Atual, 1988.

BEZERRA, M. A. Textos: seleção variada e atual. In: DIONÍSIO, A. P; BEZERRA, M. A. (Org.). O livro didático de português - múltiplos olhares. Rio de Janeiro: Lucerna, 2001.

CORACINI, M. J. (Org.). Interpretação, autoria e legitimação do livro didático. Campinas: Pontes, 1999.

CORTEZ, M. Palavra e imagem: diálogo intersemiótico. Dissertação (Mestrado) Departamento de Linguística da Faculdade de Filosofia, Letras e Ciências Humanas da Universidade de São Paulo, 2001.

GERALDI, J. W. Portos de Passagem. São Paulo: Martins Fontes, 1997.

GRIGOLETTO, M. Leitura e funcionamento discursivo do livro didático. In: CORACINI, M. J. (Org.). Interpretação, autoria e legitimação do livro didático. Campinas: Pontes, 1999.

IANNI, O. Língua e sociedade. In: VALENTE, A. (Org.). Perspectivas Inovadoras. Petrópolis: Vozes, 1999.

MARQUES NETO, J. C. Editoras universitárias brasileiras. São Paulo, 2003. Disponível em: <http://iesalc.unesco.org.ve/prueobservatorio/documentos $>$. Acesso em: 9/6/2004.

PINTO, A. M. A representação da mulher nos livros didáticos de história. Dissertação (Mestrado) - Programa de Pós-graduação do Centro Pedagógico da Universidade Federal do Espírito Santo, Vitória, 2001.

ORLANDI, E. P. Discurso e leitura. Campinas: Cortez, 1996.

SILVA, I. A. Textos verbais/visuais no livro didático de língua portuguesa: uma análise dos mecanismos de construção de sentido e da leitura proposta. Dissertação (Mestrado) - Programa de Pós-Graduação em Educação da UFES, Vitória, 2004.

Texto recebido em 30 de março de 2006. Texto aprovado em 19 de março de 2009. 